OPEN ACCESS

Edited by:

Jing Zhang,

Shanghai Jiao Tong University, China

Reviewed by:

Chenyu Lin,

The Ohio State University,

United States

Mads Thomassen,

Odense University Hospital, Denmark

*Correspondence:

Feng Yan

yanfeng@jszlyy.com.cn

Han Shen

shenhan10366@sina.com

Xinyu Tian

jipinxinyu@163.com

${ }^{\dagger}$ These authors have contributed equally to this work and share first authorship

Specialty section:

This article was submitted to Molecular and Cellular Oncology,

a section of the journal

Frontiers in Oncology

Received: 26 September 2021

Accepted: 15 November 2021

Published: 02 December 2021

Citation:

Wang T, Li Z, Yan L, Yan F, Shen H and Tian $X$ (2021) Long Non-Coding RNA Neighbor of BRCA1 Gene 2: A Crucial Regulator in Cancer Biology.

Front. Oncol. 11:783526.

doi: 10.3389/fonc.2021.783526

\section{Long Non-Coding RNA Neighbor of BRCA1 Gene 2: A Crucial Regulator in Cancer Biology}

\author{
Ting Wang ${ }^{1+}$, Zhaosheng $\mathrm{Li}^{1 \dagger}$, Liujia Yan ${ }^{1}$, Feng Yan $^{1 *}$, Han Shen ${ }^{2 *}$ and Xinyu Tian ${ }^{2 *}$ \\ 1 Department of Laboratory Medicine, Jiangsu Cancer Hospital \& Jiangsu Institute of Cancer Research \& The Affiliated \\ Cancer Hospital of Nanjing Medical University, Nanjing, China, ${ }^{2}$ Department of Laboratory Medicine, Nanjing Drum Tower \\ Hospital, Nanjing University Medical School, Nanjing, China
}

Long non-coding RNAs (IncRNAs) are involved in fundamental biochemical and cellular processes. The neighbor of BRCA1 gene 2 (NBR2) is a long intergenic non-coding RNA (lincRNA) whose gene locus is adjacent to the tumor suppressor gene breast cancer susceptibility gene 1 (BRCA1). In human cancers, NBR2 expression is dysregulated and correlates with clinical outcomes. Moreover, NBR2 is crucial for glucose metabolism and affects the proliferation, survival, metastasis, and therapeutic resistance in different types of cancer. Here, we review the precise molecular mechanisms underlying NBR2-induced changes in cancer. In addition, the potential application of NBR2 in the diagnosis and treatment of cancer is also discussed, as well as the challenges of exploiting NBR2 for cancer intervention.

Keywords: long non-coding RNA, neighbor of BRCA1 gene 2, cancer, metabolism, epithelial-mesenchymal transition, autophagy

\section{INTRODUCTION}

Presently, it is believed that nearly $87.3 \%$ of the human genome is actively transcribed, but $<3 \%$ of the genome encodes functional proteins $(1,2)$. Transcripts devoid of protein-coding capacity are termed as non-coding RNAs (ncRNAs) $(3,4)$. LncRNAs, which were previously recognized as "transcription noise", represent a class of ncRNAs consisting of $>200$ nucleotides (5-7). To date, more than 10,000 manually annotated IncRNA genes that produce more than 15,000 lncRNAs have been identified, and their total number continues to grow rapidly, which is due to advancements in RNA sequencing, epigenomic technologies, and computational prediction techniques $(2,8,9)$. Furthermore, the increasing numbers of lncRNAs have drawn increased attention to understanding their roles in biology. The lncRNA family is heterogeneous, and individual members can be classified according to their location, structure, function, and transcription orientation (10-12). For instance, based on their location in reference to protein-coding messenger RNAs (mRNAs), lncRNAs can be classified as antisense lncRNAs, lincRNAs, bi-directional lncRNAs, sense lncRNAs, and intronic IncRNAs $(6,13)$. Similar to mRNAs, the transcription of most lncRNAs is induced by RNA polymerase II, which is accompanied by $5^{\prime}$-capping, $3^{\prime}$-polyadenylation, and splicing (14-16). Although not translated, lncRNAs are emerging as essential modulators of cellular processes through the regulation of chromatin dynamics, gene expression, and protein function $(7,17-20)$. Functions of lncRNAs are closely associated with their intracellular distribution. LncRNAs in the 
cytoplasm can interact with mRNAs and proteins, thereby regulating the translation, degradation, and splicing of mRNAs, and inducing changes in protein activity and stability. LncRNAs can also function as "sponges" of microRNAs (miRNAs) in the cytoplasm, leading to the overexpression of miRNA target molecules. For lncRNAs localized in the nucleus, they can recruit transcription activators/repressors to the target gene promoter, thereby facilitating transcriptional activation/silencing. Nuclear lncRNAs can also decoy transcription factors (TFs), resulting in transcriptional inactivation. Moreover, nuclear lncRNAs can induce epigenetic modifications of target genes to regulate their expression (15, 21-25).

Cancer is a complicated disease that associates with a variety of genetic mutations, epigenetic alterations, and chromosomal translocations/deletions/amplifications (26-30). Numerous lncRNAs have been identified as oncogenes or tumor suppressors in a wide range of solid tumors and hematological malignancies, implying that $\operatorname{lncRNAs}$ are master regulators in cancer $(11,31,32)$. LncRNAs are involved in the regulation of cancer cell proliferation, survival, invasion, and metastasis, as well as the antitumor immune response (33-40). Furthermore, the dysregulated expression of lncRNAs in cancer is associated with the clinical outcome and prognosis of cancer patients (4144). Among these lncRNAs, NBR2 is a newly defined lincRNA whose expression is induced by energy stress in the tumor microenvironment (TME) and participates in cancer development (45). Here, we review the role of lncRNA NBR2 in cancer biology, as well as emphasize its clinical application.

\section{IDENTIFICATION OF THE NBR2 GENE}

NBR2 is a non-protein-coding gene on human chromosome $17 \mathrm{q} 21$ that spans $\sim 30 \mathrm{~kb}$ of genomic DNA and resides adjacent to the $B R C A 1$ gene $(45,46) . B R C A 1$ is a tumor suppressor gene which encodes a nuclear protein that can maintain genome integrity, and germline mutations of the BRCA1 gene are responsible for most familial cases with breast and ovarian cancer (46-50). To date, more than 100 distinct germline mutations in the coding region of the BRCA1 gene have been confirmed (51-53). Different from other tumor suppressor genes with both germline and somatic mutations, there are rare somatic mutations in the BRCA1 gene in breast and/or ovarian cancers. Therefore, BRCA1 mutations in the coding region are not involved in the development of sporadic cancers, and alternative inactivating mechanisms, such as promoter mutation and DNA hypermethylation, may be involved in the dysregulation of the BRCA1 gene in sporadic human cancers. Thus, studies aimed at determining the regulation of the $B R C A 1$ gene are warranted $(46,51,53)$. Previous studies, which investigated the $5^{\prime}$ region of the BRCA 1 gene in considerable detail, have revealed the transcription start sites for both $B R C A 1$ and neighbor of BRCA1 gene 1 (NBR1) genes. The genomic region housing the $5^{\prime}$ ends of BRCA1 and NBRI genes is duplicated, as a partial copy of the genomic region encompassing exons $1 \mathrm{~A}, 1 \mathrm{~B}$, and 2 of the BRCA1 gene lies headto-head with the NBR1 gene. Meanwhile, a partial copy of the $N B R 1$ gene, consisting of exons $1 \mathrm{~A}, 1 \mathrm{~B}$, and 3 , resides adjacent to the transcription start site of the $B R C A 1$ gene, and this partial copy is identified as a part of the NBR2 gene that is situated in the genomic region between $B R C A 1$ and pseudo-BRCA1 (BRCA1P1) genes and lies head-to-head with the BRCA1 gene (Figure 1) $(46,54,55)$. Despite high sequence homology at the $5^{\prime}$ ends of NBR1 and NBR2 genes, the remaining sequence regions show low homology. The NBR1 gene has been identified to encode a protein of 966 amino acid residues, which acts as a receptor for the selective autophagosomal degradation of ubiquitinated targets $(56,57)$. NBR1 is also associated with endosomal membranes by mediating the delivery of certain cargoes. In terms of expression, NBR1 is expressed in all tissues with the highest level in thyroid and testis. There has been little information about the role of NBR1 in cancer. The expression of NBR1 mRNA shows low cancer specificity, and there are weak to moderate NBR1 protein level in cytoplasm of different cancer cells. Decreased NBR1 mRNA level is associated with a poor clinical outcome in patients with clear cell renal carcinoma, indicating NBR1 mRNA level is negatively related with the prognosis of cancer patients. However, other findings revealed the properties of NBR1 in promoting cancer migration and metastasis, and in inducing tumor immune escape by

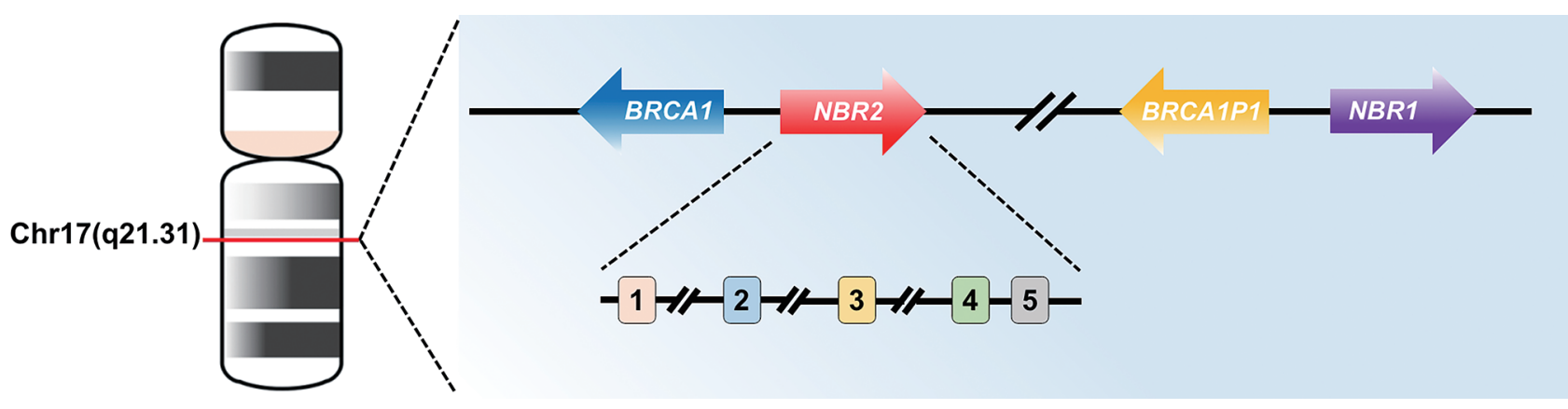

FIGURE 1 | Localization and genomic structure of the human NBR2 gene. Schematic diagram of the human NBR2 gene, with arrows indicating the direction of transcription and rectangles representing the exons. Genes are not drawn to scale. 
distributing major histocompatibility complex-I (MHC-I) on the cell surface. Therefore, the role of NBR1 in cancer is complicated and needs further investigations (58). Different from the NBR1 gene, the transcript encoded by the NBR2 gene is an lncRNA, and its expression has been identified in most examined tissues, including the spleen, thymus, prostate, testis, ovary, small intestine, colon, and peripheral blood leukocytes $(46,59,60)$. A previous study has reported that there is an open reading frame (ORF) of 112 amino acid residues in the NBR2 cDNA that was predicted to encode a $\sim 12-\mathrm{kD}$ a protein. However, a strong Kozak signal has not been observed within this ORF, and the stop codon is located $>55$ bp upstream of the last splicing site for the putative NBR2 ORF. Therefore, these findings suggest that the NBR2 transcript may have been degraded by nonsense-mediated mRNA decay, although it is subjected to protein synthesis $(46,51)$.

\section{REGULATION OF NBR2 EXPRESSION IN CANCER}

The NBR2 gene, which is located between BRCA1 and BRCA1P1 genes, shows less conservation across species, as it has only been identified in primates but not in other species, including mice. Consistent with the BRCA1 gene, NBR2 expression is usually down-regulated in cancer. In a single-strand conformation polymorphism (SSCP) analysis, it was revealed that the NBR2 gene shows no mutations in both breast and ovarian cancers, suggesting that the involvement of the NBR2 gene in these cancers is not concerned with gene mutations (46). Sequence analysis of the NBR2 gene reveals that it contains five exons, in which the last exon is alternatively used and is transcribed in the opposite direction from that of the BRCA1 gene. The transcription of two distinct BRCA1 transcripts $\alpha$ and $\beta$, in which exon $1 \mathrm{~A}$ and exon $1 \mathrm{~B}$ are the first exons, respectively, is achieved by their respective promoters $\alpha$ and $\beta$. Promoter $\alpha$ of the BRCA1 gene is defined to be bi-directional, and cis-control elements in the intergenic region of BRCA1 and NBR2 genes dominate promoter $\alpha$ activity, as promoter $\alpha$-induced transcription of both $B R C A 1$ and $N B R 2$ genes is regulated by enhancers and silencers located in the region between nucleotide positions 1 and 1357. Moreover, the TF binding sites in the BRCA1/NBR2 promoter have been delineated. Therefore, the expression of $B R C A 1$ and $N B R 2$ genes can be affected by different TFs, dominated by cis-elements in the intergenic region, and regulated by the availability of these TFs during development and tumorigenesis $(54,61,62)$.

The analysis of the DNA sequence homology in the region that encompasses both the bi-directional promoter and the $B R C A 1$ promoter $\beta$ (nucleotide positions 1191 to 2052) indicates a role for the CCAAT element in the coordinated activation of both BRCA1 and NBR2 genes (62). Other elements that can modulate the transcription of BRCA1 and NBR2 genes have also been identified (63-65). In the intergenic region between BRCA1 and NBR2 genes, a minimal 56-bp EcoRIHaeIII fragment has been delineated to act as a bi-directional promoter and it induces transcription in the NBR2 gene direction 2-4-fold higher than that in the BRCA1 direction in all tested cell lines (including cervical carcinoma, colon carcinoma, and mammary carcinoma cells). Within this sequence, the potential binding sites for TFs of the E-twentysix (ETS) family, Sp1 transcription factor (SP1) family, and cAMP-responsive element-binding protein (CREB) have been defined. In addition, a specific protein-DNA complex was identified when this 56-bp EcoRI-HaeIII minimal promoter was incubated with nuclear extracts from cancer cells. Moreover, the 56-bp minimal promoter can be further divided into 38-bp EcoRI-MspI and 18-bp MspI-HaeIII fragments, and tissue-specific factor binding to MspI-HaeIII is required for $B R C A 1$ transcription (65). Another 36-bp BstNI-BseRI fragment, which is 575-bp into the first intron of the BRCA1 gene, exhibits non-tissue-specific transcriptional suppressor activity by interacting with specific nuclear proteins. However, this putative negative regulatory element (NRE) only blocks transcription in the BRCA1 direction, although the promoter is shared by the divergently transcribed NBR2 gene (63). For the $N B R 2$ gene, an 18-bp transcriptional repressive element, which resides 948-bp into its first intron, was recently identified. The interaction between nuclear proteins and this 18-bp HaeIIIHaeIII repressive element was confirmed by electrophoretic mobility shift assays (EMSAs), and functional suppression was conferred to the heterologous thymidine kinase promoter by this element. In addition, this repressive element had no effect on the $B R C A 1$ direction in the context of its native genomic organization (64). Therefore, a model of the BRCA1-NBR2 bidirectional transcription unit is established, in which the minimal 56-bp DNA region functions to drive the transcription in both directions and the uni-directional transcription is controlled by distinct repressors binding to elements in the first intron of respective genes (Figure 2A).

Specific molecules that regulate NBR2 transcription by interacting with corresponding regulatory elements have been identified. For instance, methyl-CpG binding domain protein 2 (MBD2) specifically binds to the methylated region of the repeated LTR12c element at the BRCA1-NBR2 locus, which leads to the silencing of the NBR2 gene (66). MBD2 is a member of the MBD protein family, which are key molecules that participate in the interpretation of DNA methylation, leading to gene silencing (67). In the study by Auriol E et al., $\mathrm{MBD} 2$ was found to bind to the methylated region of the $\mathrm{CpG}$ island flanking the bi-directional BRCA1-NBR2 promoter in HeLa cells, but not the unmethylated region. Meanwhile, the methylated region of the BRCA1 island was not bound by other $\mathrm{MBD}$ proteins, such as methyl-CpG binding protein 2 (MeCP2) and MBD1, implying that the binding of MBD2 is specific. The $B R C A 1-N B R 2$ locus-bound MBD2 induced the specific methylation-dependent repression of $N B R 2$, whereas it did not affect the transcription of $B R C A 1$ (Figure 2B) (66). In addition to the regulation of $N B R 2$ expression at the transcriptional level, the modulation of the expression of this lncRNA at the post-transcriptional level has also been identified. In acute liver failure (ALF), increased $m i R-19 a$ expression is accompanied by 


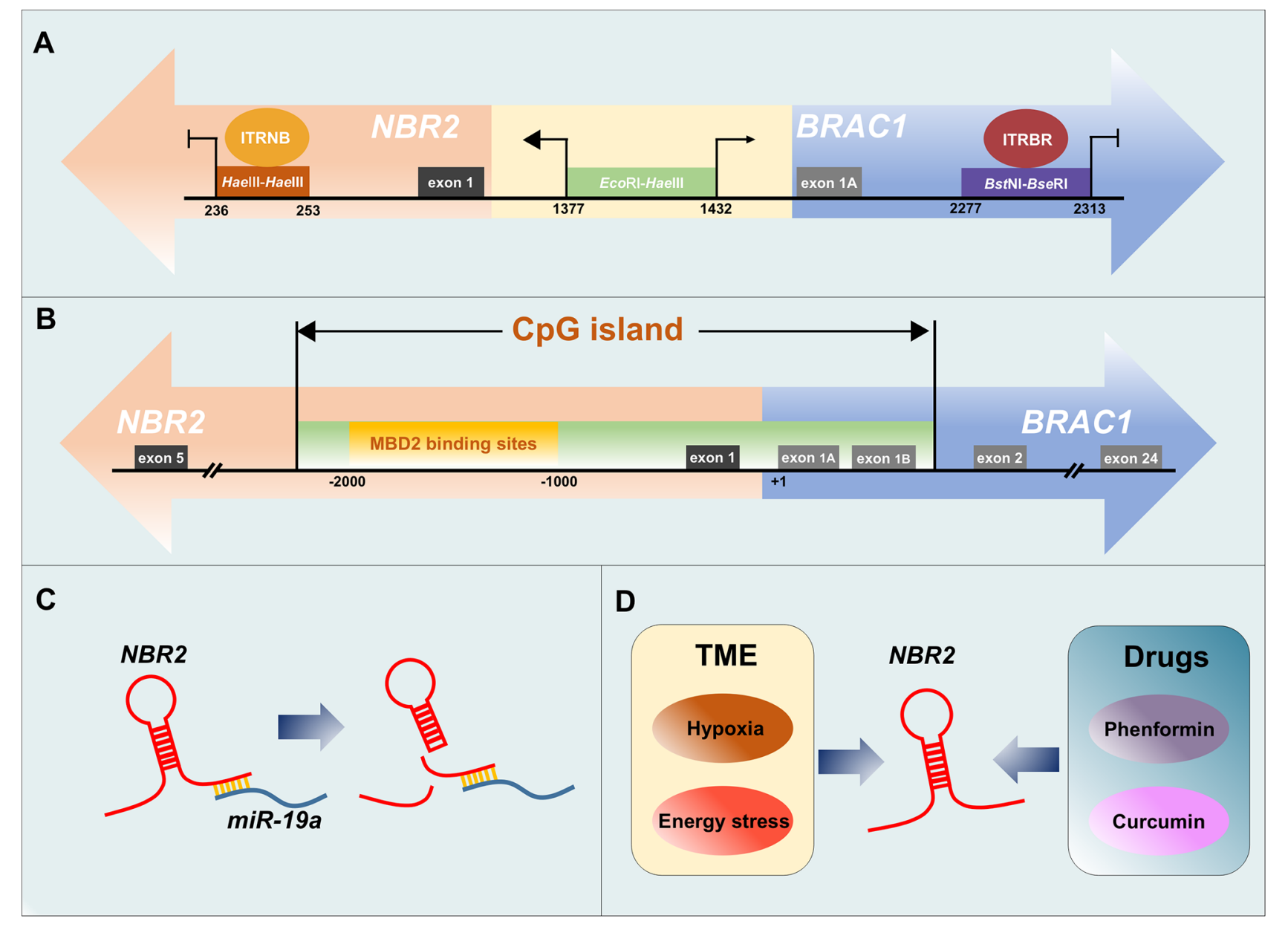

FIGURE 2 | Regulation of NBR2 expression in cancer. (A) Model of the BRCA1-NBR2 bi-directional transcription unit. A minimal 56-bp EcoRI-Haell fragment (nucleotides 1377-1432) located between NBR2 and BRCA1 genes acts as a bi-directional promoter, and it induces transcription in the NBR2 gene direction higher than that in the BRCA1 direction. An 18-bp Haell-Haell repressive element (nucleotides 236-253) that resides 948-bp into the first intron of the NBR2 gene and is bound by the intronic transcriptional repressor of NBR2 (ITRNB) functions to turn off transcription only in the NBR2 direction. The 36-bp BstNI-BseRl fragment (nucleotides 2277-2313) that resides 575-bp into the first intron of the BRCA1 gene exhibits non-tissue-specific transcriptional suppressive activity only in the BRCA1 direction by binding to the intronic transcriptional repressor of BRCA1 (ITRBR). (B) MBD2 leads to the silencing of the NBR2 gene by binding specifically to the methylated region of the $\mathrm{CpG}$ island flanking the bi-directional BRCA1-NBR2 promoter. Positions are indicated from the BRCA1 transcription start site. (C) MiR$19 a$ can interact with NBR2 and induce its degradation. (D) Some exogenous factors, such as hypoxia/energy stress in TME and antitumor drugs, can induce the expression of NBR2.

decreased NBR2 expression. MiR-19a can interact with NBR2 and protein kinase AMP-activated catalytic subunit alpha 1 (PRKAA1) (the gene encodes adenosine 5'-monophosphate (AMP)-activated protein kinase (AMPK)), and down-regulate the levels of both NBR2 and AMPK in injured hepatocytes, thereby inhibiting autophagy in hepatocytes (Figure 2C) (59).

In addition to these endogenous regulatory patterns, NBR2 expression can also be mediated by exogenous factors such as TME conditions and antitumor drugs. TME is a complex network consisting of a variety of cell types and factors, which is essential for tumor progression (68). Hypoxia, which is a common feature of TME and critical for the evolution of malignant cells, can affect BRCA1 and NBR2 expression differently. Hypoxia results in histone modifications at the endogenous BRCA1 promoter in human breast cells, thereby repressing $B R C A 1$ transcription, whereas it induces the activation of NBR2 transcription from the bi-directional $B R C A 1$ promoter. Different regulatory elements drive the hypoxia-induced repression of $B R C A 1$ and the activation of NBR2 in cancer cells. It has been reported that hypoxiainduced silencing of the 218-bp minimal promoter is responsible for $B R C A 1$ down-regulation, whereas elements that control NBR2 expression are beyond this minimal promoter and remain to be determined $(69,70)$. In addition, glucose starvation in TME can also induce the expression of lncRNA NBR2 in cancer cells through the liver kinase B1 (LKB1)-AMPK pathway, and the precise mechanism will be discussed in the next section (45). Several antitumor drugs, such as phenformin and 
curcumin, have been reported to induce NBR2 expression in cancer, although the precise regulatory mechanisms remain unknown (Figure 2D) (71, 72). NBR2 is involved in cancer progression based on its ectopic expression. Therefore, we place an emphasis on the NBR2-indued regulatory mechanisms in tumorigenesis in the following section.

\section{FUNCTIONS OF NBR2 IN CANCER BIOLOGY}

In consideration of the high mutation/deletion rate of the $B R C A 1$ gene in human breast and ovarian cancers, the NBR2 gene, which is proximal to the $B R C A 1$ gene, was initially presumed to be codeleted/mutated with BRCA1 in certain cancers. Thus, NBR2 may also play a role in tumor suppression similar to BRCA1. However, NBR2 was later confirmed to be a lncRNA, and its complicated roles in tumor biology are being revealed gradually $(45,51,73)$.

\section{Dual Role of NBR2 in Regulating Glucose Metabolism}

The study by Liu X et al. identified the role of lincRNA NBR2 in tumor suppression for the first time, and it was confirmed that energy stress-induced NBR2 interacts with AMPK and potentiates AMPK activity under a condition of energy stress $(45,51,73)$. Glucose deprivation in TME can subsequently result in increased cell apoptosis and decreased cell migration and invasion. However, to resist energy stress-induced apoptosis, cancer cells can adjust to the nutrient-limited environment and develop compensatory ways through metabolic reprogramming. Different from normal cells, cancer cells exhibit increased glucose uptake, aerobic glycolysis, enhanced glutamine uptake and glutaminolysis, and changes in lipid metabolism $(60,74)$. The findings of Liu $\mathrm{X}$ et al. were derived from the identification and investigation of energy stress-induced lncRNAs. To verify the lncRNA expression profile induced by energy stress, RNA sequencing was conducted in carcinoma cells cultured in medium with or without glucose. NBR2 was identified as one of the glucose starvation-induced lincRNAs in the subsequent computational analysis, and its expression induced by energy stress was partly dependent on the LKB1-AMPK pathway. Furthermore, NBR2 was demonstrated to regulate AMPK activity via a direct interaction (45). AMPK is a heterotrimeric complex containing a catalytic $\alpha$ subunit and two regulatory $\beta$ and $\gamma$ subunits (75). Stress-induced NBR2 interacted with AMPK $\alpha$ of the AMPK complex through its first exon and enhanced the activity of AMPK kinase, which is parallel to LKB1-induced AMPK activation. Notably, NBR2 was not required for initial energy stress-induced AMPK activation. Therefore, the feedback mechanism responsible for NBR2AMPK regulation in both breast and kidney cancer cells under glucose-starvation conditions was revealed. AMPK is a crucial checkpoint of metabolism. Under conditions of energy stress, AMPK signaling is activated to facilitate catabolic processes (such as autophagy, fatty acid oxidation, glycolysis) and suppress anabolic processes (such as sterol/lipid/protein synthesis), thereby leading to restored energy balance. Mammalian target of rapamycin complex 1 (mTORC1)induced protein synthesis and cell growth are major anabolic processes inhibited by AMPK in response to energy stress (76, 77), and energy stress-induced AMPK can also promote autophagy by directly activating the Unc-51 like autophagy activating kinase 1 (ULK1) through the phosphorylation of serine (Ser) 317 and Ser 777 (78). Therefore, the AMPK pathway functions to suppress cancers, as anabolic processes are necessary for tumor progression. Consistent with this finding, NBR2 led to decreased cell cycle progression, but increased autophagy, which down-regulated apoptosis under energy stress and inhibited the progression of breast and kidney cancers, suggesting that NBR2 is a tumor suppressor that regulates AMPK activity. Accordingly, the NBR2 level was down-regulated in breast and kidney cancer patients and was negatively correlated with poor prognosis $(45,51,73)$. In colorectal cancer (CRC), the NBR2-AMPK pathway is involved in curcumin-mediated CRC progression. It has been reported that glucose starvation induces the expression of NBR2 in CRC cells, at least partly through an AMPK-dependent manner. NBR2 overexpression results in the activation of the AMPK-mammalian target of rapamycin kinase (mTOR) pathway under glucose-starvation conditions, thereby affecting CRC progression (72). Curcumin, a compound isolated from the rhizomes of Curcuma longa, has been approved for the intervention of human cancers, including CRC (79). Curcumin shows a synergetic effect with glucose starvation in regulating the AMPK-mTOR pathway. Similar to glucose deficiency, curcumin induces NBR2 expression in CRC cells. The increased NBR2 enhances the curcumin-mediated suppression of the proliferation and clone formation of CRC cells through the activation of the AMPK-mTOR pathway, providing new insights for CRC therapy (Figure 3) (72).

In addition to affecting the activation of the AMPK pathway, lncRNA NBR2 can mediate the glucose metabolism of cancer cells by other mechanisms. In breast and kidney cancer cells, NBR2 regulates cancer cell sensitivity to phenformin through glucose transporter 1 (GLUT1). Phenformin is an inhibitor of mitochondrial respiratory chain complex I, and its antitumor effect is more potent than that of metformin. Phenformin induces NBR2 expression in breast and kidney cancer cells, and $N B R 2$ deficiency renders cancer cells more sensitive to phenformin-induced apoptosis. Thus, NBR2 expression may function as an adaptive response to maintain cell survival after phenformin treatment. It is well established that phenformin enhances the activation of AMPK and the inactivation of mTORC1, and the inhibition of the AMPK pathway renders cancer cells more sensitive to phenformin-induced cell death. However, even if NBR2 promotes energy-induced AMPK activation through direct interaction, the interaction of NBR2 with AMPK is not influenced by phenformin, and phenformin induces AMPK activation independent of NBR2. On the other hand, NBR2 deficiency suppresses glucose uptake through the inhibition of phenformin-induced GLUT1 expression, which is 


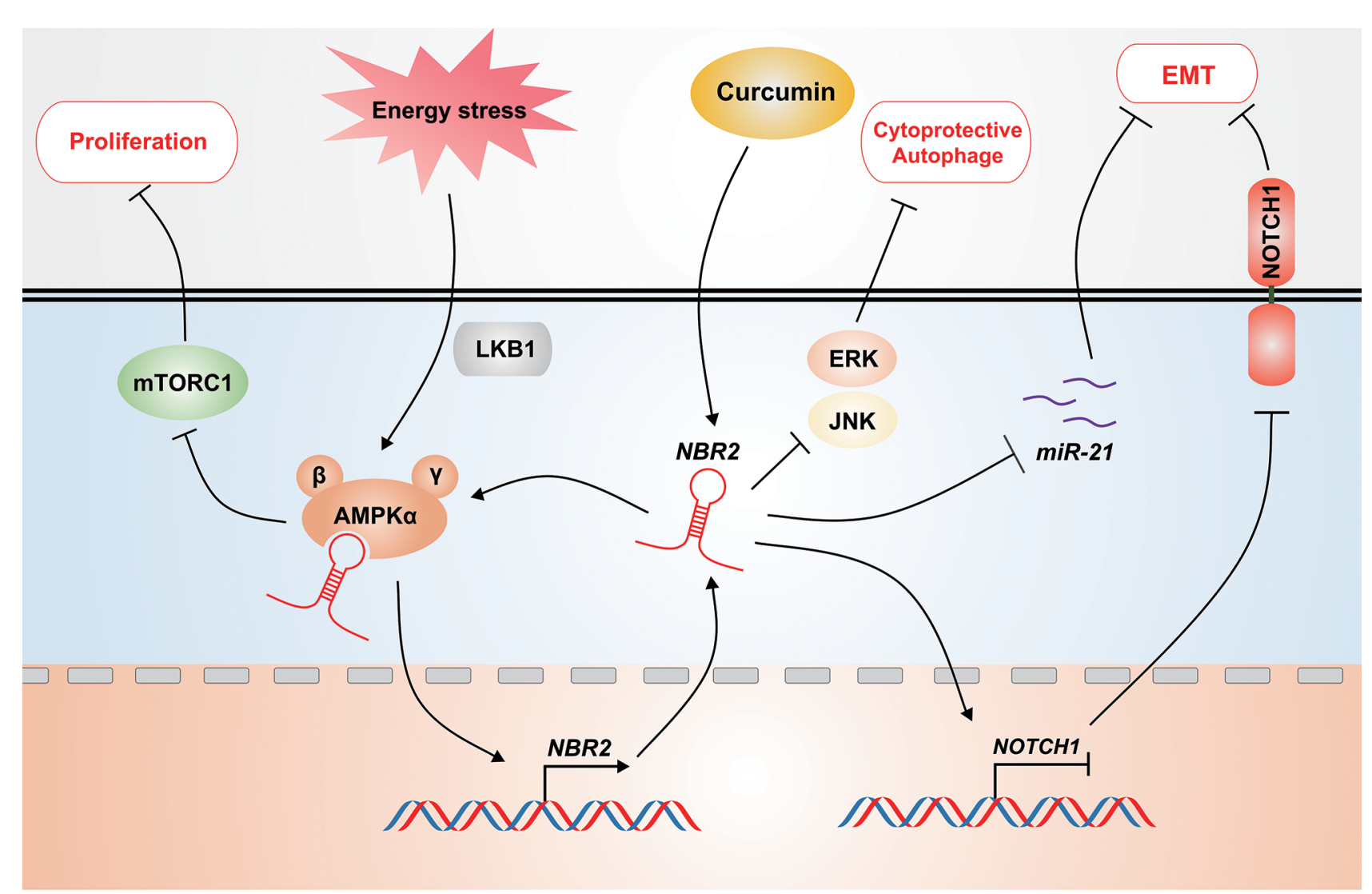

FIGURE 3 | NBR2 functions as a tumor suppressor. NBR2 is responsible for the glucose metabolism in cancer dependent on the AMPK-mTOR pathway. Glucose starvation in TME induces the expression of NBR2 depending on the LKB1-AMPK pathway. As feedback, stress-induced NBR2 enhances the activity of AMPK kinase by directly interacting with its AMPK $\alpha$ subunit, thereby inhibiting the proliferation of cancer cells. Based on its regulation of the AMPK-mTOR pathway, curcumin-induced NBR2 enhances the antitumor effects of curcumin by suppressing cancer proliferation and clone formation. In addition, NBR2 attenuates EMT by blocking the NOTCH1 pathway and inhibiting miR-21 expression. Moreover, NBR2 impedes Beclin1-induced cytoprotective autophagy, thereby inhibiting cancer proliferation through ERK and JNK pathways.

the glucose transporter with the most relevance to cancer biology, as it is overexpressed in many human cancers. It has been observed that GLUT1 deficiency sensitizes cancer cells to phenformin-induced cell death, whereas GLUT1 restoration in NBR2-deficient cells rescues the increased cell death after phenformin treatment. This finding identifies a new mechanism of NBR2 modulation of glucose metabolism in cancer cells, suggesting that NBR2 may predict the biguanide treatment response in cancer patients $(71,80)$. Furthermore, it reveals the opposite role of lncRNA NBR2 in cancer development, which is contrary to the initial view that NBR2 functions as a tumor suppressor. Consistently, NBR2 has recently been identified to aggravate hepatoblastoma cell malignancy. NBR2 expression is significantly increased in hepatoblastoma tissues, and glucose starvation is required for this up-regulation. The deficiency of $N B R 2$ suppresses the invasion, migration, and viability of hepatoblastoma cells cultured under normal conditions, and facilitates cell apoptosis under glucose starvation. As the most common pediatric liver malignancy, hepatoblastoma is believed to be a Wnt- $\beta$-catenin-activated malignant tumor, with frequent mutations in the catenin beta 1 (CTNNB1) gene that encodes $\beta$ catenin. Within mammalian cells, the activation of Wnt- $\beta$-catenin pathway leads to $\beta$-catenin accumulation in the cytoplasm and its translocation into the nucleus to facilitate the transcriptional activation of the T-cell factor (TCF) family (81-83). TCF7 has been reported to be co-expressed with NBR2, and NBR2 deficiency leads to decreased TCF7 expression in hepatoblastoma cells, along with the down-regulation of the TCF7 protein that is involved in cell cycle progression, glucose entrapment, and epithelialmesenchymal transition (EMT). The main regulatory mechanism of lncRNAs in the cytoplasm is to act as competing endogenous RNAs (ceRNAs) to sponge miRNAs. TCF7 has been defined as the target molecule of $m i R-22$ and NBR2, which is localized in both the cytoplasm and nucleus, aggravates hepatoblastoma cell malignancy by sponging $m i R-22$ under conditions of glucose starvation, thereby counteracting $m i R-22$ induced TCF7 repression (Figure 4) (60). The above studies reveal the double-edged sword role of lncRNA NBR2 in regulating the glucose metabolism of different cancers, further emphasizing its importance in maintaining the energy balance. 


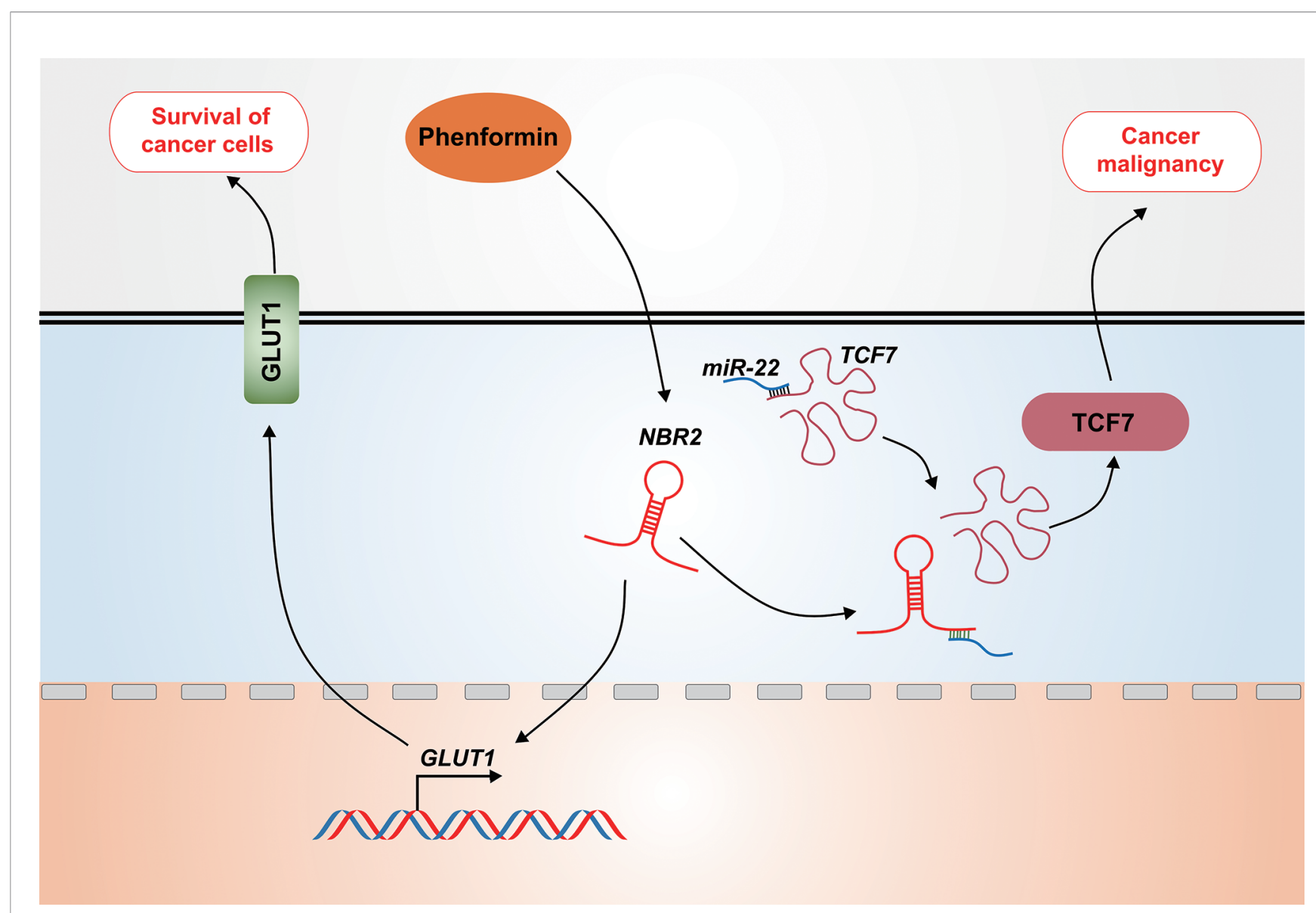

FIGURE 4 | Opposite roles of NBR2 in cancer. NBR2 functions as an adaptive responser that maintains cell survival in response to phenformin treatment by facilitating GLUT1 expression. In addition, NBR2 in the cytoplasm sponges miR-22 under conditions of glucose starvation, thereby counteracting miR-22-induced TCF7 repression and aggravating the malignancy of hepatoblastoma cells.

\section{NBR2 Suppresses EMT in Cancer}

EMT is a process that is critical for wound healing, embryogenesis, and malignancy. During EMT, cell-extracellular matrix and cellcell interactions are reprogrammed, which leads to the separation of epithelial cells from adjacent cells and the basement membrane, and new transcriptional events are induced to promote the mesenchymal fate. In cancer progression, EMT contributes to tumor initiation, metastasis, and therapeutic resistance, which is regulated by crucial TFs such as zinc-finger E-box-binding (ZEB) TFs and SNAIL. Both transcriptional reprogramming and nontranscriptional changes during EMT are induced by pathways responding to extracellular molecules $(84,85)$. Currently, lncRNAs are emerging as crucial regulators of EMT that can determine cancer progression (86). NBR2, an lincRNA that was initially identified as a cancer suppressor, is involved in the regulation of EMT in different cancers (Figure 3) (87-90).

In non-small cell lung cancer (NSCLC), the NBR2 level is low in tumor tissues and is correlated with tumor size and prognosis. NBR2 overexpression inhibits the proliferation, invasion, and migration of NSCLC cells. A mechanistic study has revealed that NBR2 inhibits EMT in NSCLC by suppressing the notch receptor
1 (NOTCH1) pathway (87). During the development of osteosarcoma, cancer patients with low NBR2 expression exhibit a shorter overall survival compared to those with high NBR2 expression. NBR2 inhibits the proliferation, invasion, and migration of osteosarcoma cells, but has no effect on cell apoptosis, thereby delaying tumor growth. NBR2 has also been identified to function as an EMT suppressor by regulating NOTCH1 at both transcriptional and post-transcriptional levels in osteosarcoma (89). Similarly, the NBR2 level is decreased in thyroid cancer (TC) tissues and cells, and it is associated with the histologic subtypes of TC. NBR2 overexpression significantly suppresses TC proliferation, clonogenicity, and invasion as well as tumor growth in vivo, whereas NBR2 knockdown has the opposite effects. Mechanistic studies have revealed that NBR2 inhibits GLUT1 expression and EMT, but promotes AMPK and acetyl-CoA carboxylase (ACC) activation in TC cells, thereby reducing the malignancy of TC and acting as a tumor suppressor $(90,91)$. In colorectal cancer, the low NBR2 level has been reported in tumor tissues, and decreased NBR2 expression is associated with the progression of clinical stages. The expression of $m i R-21$, which is a cancer promoter, is 
increased in colorectal cancer tissues and inversely correlated with the NBR2 level. Moreover, NBR2 overexpression inhibits $m i R-21$ expression in colorectal cancer cells and attenuates colorectal cancer cell migration and invasion, whereas $m i R-21$ has no influence on NBR2 expression (88). These findings revealing the role of NBR2 in EMT further confirm that NBR2 may be a potential target for cancer diagnosis and treatment.

\section{NBR2 Regulates the Autophagy of Cancer Cells}

Autophagy is a conserved catabolic process. It is initiated by the formation of autophagosomes, which encapsulate the cytoplasm and organelles, and then form autolysosomes by fusing with lysosomes, thereby leading to the degradation of the contents contained within the vesicles (92). Autophagy mediates the proliferation and apoptosis of liver cells in different contexts, and it has been confirmed that protective autophagy is the main cause of cancer survival in an adverse environment $(93,94)$. In addition to affecting the metabolism and EMT, NBR2 can also inhibit tumorigenesis by regulating autophagy. It has been demonstrated that in hepatocellular carcinoma (HCC) patients at advanced clinical stages, the overall survival of cases with low $N B R 2$ expression is significantly worse compared to those with high NBR2 expression. As such, NBR2 acts as a negative regulator of HCC, as it inhibits cancer proliferation, invasion, and migration. Cell death is a complicated process, for which autophagy, as well as apoptosis, is essential. NBR2 regulates autophagy, but not apoptosis, of HCC cells. Basal autophagy suppresses tumor progression by maintaining cellular homeostasis. However, protective autophagy enhances the survival of cancer cells to facilitate tumor development in TME. Therefore, an inhibition of autophagy may be an ideal approach for cancer treatment. In HCC, NBR2 attenuates Beclin1-induced cytoprotective autophagy to inhibit cancer proliferation through the extracellular regulated protein kinase (ERK) and c-Jun N-terminal kinase (JNK) pathways, which provides novel insights on a treatment strategy for $\operatorname{HCC}(95,96)$.

\section{CLINICAL APPLICATIONS OF NBR2 IN CANCER}

Similar to BRCA1, the potential application of NBR2 as a cancer biomarker was initially revealed in breast cancer, as the expression of NBR2 decreased in primary cancer cells derived from human breast cancer tissues (61). Subsequent studies further confirmed this finding and showed that low NBR2 expression correlates with poor clinical outcomes in breast and ovarian cancer patients (45, 97). Furthermore, a common breast cancer risk loci, rs9911630, is identified to be the most strongly expression-associated genotyped single nucleotide polymorphism (SNP) that affects the expression of BRCA1 and NBR2 in the Tunisian population, but whether this $\mathrm{SNP}$ is responsible for NBR2 expression in other populations is still not clear (98). Germline mutations in the coding region of the $B R C A 1$ gene are responsible for familial breast and ovarian cancers (51-53). Different from BRCA1, there is no mutation in the NBR2 gene (46). However, it has been demonstrated that the deletion of the NBR2 gene may be closely related to the susceptibility of breast and ovarian cancers in different populations. For example, germline $B R C A 1$ promoter deletions have been confirmed in familial breast cancer patients from the United Kingdom and Australia. The breakpoints for this deletion are in BRCA1 intron 2 and between NBR2 and BRCA1P1 exon 2, suggesting that this deletion takes place through a novel mechanism involving the recombination of BRCA1:BRCA1P1 (99). In a French breast-ovarian cancer family, a novel rare 161$\mathrm{kb}$ deletion in the region extending from the NBR1 gene to the $B R C A 1$ gene was identified. This deletion encompassed NBR1, $B R C A 1 P 1, N B R 2$, and $B R C A 1$ genes, and it started from the Alu Y sequence of NBR1 intron 18 and ended at the Alu Sc sequence of $B R C A 1$ intron 22 . The hemizygosity of the four genes showed no specific phenotype (100). For sporadic breast cancer, a de novo complete BRCA1 gene deletion, which includes Rho family GTPase 2 (RND2), BRCA1P1, BRCA1, and NBR2 complete genes, has been reported in a Spanish woman with early bilateral breast cancer, supporting the large genomic rearrangement screening of $B R C A$ genes in young breast cancer patients without a family history, as well as in hereditary breast and ovarian cancer families previously tested negative for other variations (101). In an Italian woman diagnosed with high-grade serous ovarian carcinoma, the deletion of a 137.8-kb region, encompassing the first six exons of the BRCA1 gene and the full length of NBR2, BRCA1P1, NBR1, and transmembrane protein 106A (TMEM106a) genes, was detected (102). In addition to breast and ovarian cancers, dysregulated NBR2 expression and function have also been observed in some other solid tumors (Table 1). Consistently, the NBR2 level was associated with the progression of these cancers $(72,80,89,90,95,97)$. For instance, the NBR2 level in advanced HCC patients is correlated with overall survival (95). These studies suggest that NBR2 is a potential biomarker for monitoring cancer development.

$N B R 2$ is also a promising therapeutic target, as NBR2 is involved in regulating the proliferation, migration, and survival of different cancer cells $(45,87,90,95)$. Moreover, NBR2 affects cancer cell sensitivity to antitumor drugs, as NBR2 expression is related to drug resistance (104). As mentioned above, NBR2 deficiency renders cancer cells more sensitive to phenformin through the inhibition of GLUT1 expression, suggesting that the NBR2-GLUT1 axis may serve as an adaptive response for phenformin treatment $(71,80)$. In CRC, increased NBR2 expression enhances the antitumor effect of curcumin by activating the AMPK-mTOR pathway (72). Therefore, it is conceivable to expand the utilization of NBR2 in antitumor therapies.

\section{CHALLENGES AND FUTURE DIRECTIONS}

Despite considerable progress in the understanding of NBR2 function, significant obstacles remain to be overcome for better realizing the role of $N B R 2$ in cancer. One challenge is the lack of a high-resolution map of NBR2's interactions with its partners. LncRNA regulation is associated with its location in cells, and 
TABLE 1 | Clinical applications of NBR2 in cancer.

\begin{tabular}{|c|c|c|c|c|}
\hline Cancer type & Role of $N B R 2$ & Outcome & Potentialapplication & Refs \\
\hline Glioma & Oncogene & $\begin{array}{l}\text { Viability } \uparrow \\
\text { Proliferation } \uparrow \\
\text { Migration } \uparrow \\
\text { Invasion } \uparrow\end{array}$ & $\begin{array}{l}\text { Diagnosis } \\
\text { /Prognosis } \\
\text { /Therapy }\end{array}$ & $(103)$ \\
\hline Hepatoblastoma & Oncogene & $\begin{array}{l}\text { Viability } \uparrow \\
\text { Proliferation } \uparrow \\
\text { Migration } \uparrow \\
\text { Invasion } \uparrow\end{array}$ & $\begin{array}{l}\text { Diagnosis } \\
\text { /Therapy }\end{array}$ & $(60)$ \\
\hline Hepatocellular carcinoma & Tumor suppressor & $\begin{array}{l}\text { Proliferation } \downarrow \\
\text { Migration } \downarrow \\
\text { Invasion } \downarrow \\
\text { Autophagy } \downarrow\end{array}$ & $\begin{array}{l}\text { Diagnosis } \\
\text { /Prognosis } \\
\text { /Therapy }\end{array}$ & (95) \\
\hline Thyroid cancer & Tumor suppressor & $\begin{array}{l}\text { Proliferation } \downarrow \\
\text { Clonogenicity } \downarrow \\
\text { Invasion } \downarrow \\
\text { Wound healing } \downarrow \\
\text { Apoptosis } \uparrow\end{array}$ & $\begin{array}{l}\text { Diagnosis } \\
\text { /Therapy }\end{array}$ & (90) \\
\hline Non-small-cell lung cancer & Tumor suppressor & $\begin{array}{l}\text { Viability } \downarrow \\
\text { Migration } \downarrow\end{array}$ & $\begin{array}{l}\text { Diagnosis } \\
\text { /Prognosis } \\
\text { /Therapy }\end{array}$ & $(87)$ \\
\hline Colorectal cancer & Tumor suppressor & $\begin{array}{l}\text { Invasion } \downarrow \\
\text { Migration } \downarrow \\
\text { Proliferation } \downarrow \\
\text { Curcumin sensitivity } \uparrow\end{array}$ & $\begin{array}{l}\text { Diagnosis } \\
\text { /Prognosis } \\
\text { /Therapy }\end{array}$ & (88) \\
\hline Ovarian cancer & Tumor suppressor & - & Prognosis & $(97)$ \\
\hline Osteosarcoma & Tumor suppressor & $\begin{array}{l}\text { Proliferation } \downarrow \\
\text { Migration } \downarrow \\
\text { Invasion } \downarrow\end{array}$ & $\begin{array}{l}\text { Diagnosis } \\
\text { /Prognosis } \\
\text { /Therapy }\end{array}$ & (89) \\
\hline $\begin{array}{l}\text { Breast \& } \\
\text { Renal cancer }\end{array}$ & Tumor suppressor & $\begin{array}{l}\text { Proliferation } \downarrow \\
\text { Phenformin sensitivity } \downarrow\end{array}$ & $\begin{array}{l}\text { Diagnosis } \\
\text { /Prognosis } \\
\text { /Therapy }\end{array}$ & $(45,99-102)$ \\
\hline
\end{tabular}

Roles of NBR2 in different cancer types and its potential clinical applications. "-" represents "not identified".

$N B R 2$ has been indicated to be localized in both the cytoplasm and nucleus, prompting the diversity of $N B R 2$ regulatory mechanisms $(19,45) . N B R 2$ in the cytoplasm can promote AMPK activity by interacting with AMPK $\alpha$, thereby regulating the proliferation, apoptosis, and autophagy of cancer cells (45). However, it is still unclear whether the NBR2-AMPK complex encompasses other molecules or whether the interaction of NBR2 with other proteins has the same effect. Therefore, the identification of molecules interacting with NBR2 will be helpful for defining the functions of NBR2. Moreover, NBR2 dysregulation can regulate the expression of cancer-associated genes, such as NOTCH1 and GLUT1, suggesting that NBR2 can affect the activation of gene transcription $(71,87)$. However, the precise mechanism of NBR2 in the regulation of gene expression at the transcriptional level still needs to be investigated.

The dual role of NBR2 in cancer biology is another challenge. $N B R 2$ was initially identified as a tumor suppressor similar to $B R C A 1$, and plenty of evidence has verified this perspective (45). However, an opposite role of NBR2 in cancer progression has also been revealed. It has been reported that the NBR2 level is significantly increased in hepatoblastoma tissues, where it aggravates hepatoblastoma cell malignancy under conditions of glucose starvation through the $m i R-22-\mathrm{TCF} 7$ axis (60). Furthermore, NBR2 induces the resistance of cancer cells to phenformin treatment $(71,80)$. A recent study has also confirmed that NBR2 promotes the proliferation of glioma cells by inhibiting $p 15$ expression (103). The adverse effects of NBR2 may result from the type, stage, or genetic context of these cancers, underlining that antitumor therapeutic strategies targeting NBR2 should be applied modestly.

Lastly, based on its mutation and dysregulated expression, the BRCA1 gene is one of the most important genes for the susceptibility of breast and ovarian cancers, and its clinical application in cancer diagnosis has been reported $(50,105)$. The potential application of the NBR2 gene, which shares a bidirectional promoter with the BRCA1 gene, has also been revealed in cancer diagnosis (95). The deletion of the NBR2 gene has been reported to be associated with the susceptibility of breast and ovarian cancers in different populations. However, these deletions, which usually contain BRCA1, $N B R 2, B R C A 1 P 1$, and NBR1 genes, are not restricted to the NBR2 gene, and further studies are needed to confirm whether a specific deletion of the NBR2 gene determines cancer susceptibility.

\section{CONCLUSIONS}

NBR2 has emerged as a crucial regulator of cancer biology, and a promising diagnostic and therapeutic target. Further 
investigations underlying the NBR2 regulatory mechanisms in cancer are required for the materialization of its clinical application. Finally, these studies will improve our understanding of the roles of lncRNA in cancer through the investigation of NBR2.

\section{AUTHOR CONTRIBUTIONS}

TW, FY, and XT conceived the presented ideas and researched the background of the study. TW, ZL, and HS prepared the figures and tables. TW, LY, and XT wrote the manuscript.
All authors contributed to the article and approved the submitted version.

\section{FUNDING}

This work was supported by the National Natural Science Foundation of China (Grant No. 81802855), the Natural Science Foundation of Jiangsu Province (Grant No. BK20180123), the Jiangsu Postdoctoral Research Foundation (Grant No. 2018K253C), and the China Postdoctoral Science Foundation (Grant No. 2018ZM642225).

\section{REFERENCES}

1. Mudge JM, Frankish A, Harrow J. Functional Transcriptomics in the PostENCODE Era. Genome Res (2013) 23:1961-73. doi: 10.1101/gr.161315.113

2. Qu X, Alsager S, Zhuo Y, Shan B. HOX Transcript Antisense RNA (HOTAIR) in Cancer. Cancer Lett (2019) 454:90-7. doi: 10.1016/ j.canlet.2019.04.016

3. Matsui M, Corey DR. Non-Coding RNAs as Drug Targets. Nat Rev Drug Discov (2017) 16:167-79. doi: 10.1038/nrd.2016.117

4. Cech TR, Steitz JA. The Noncoding RNA Revolution-Trashing Old Rules to Forge New Ones. Cell (2014) 157:77-94. doi: 10.1016/j.cell.2014.03.008

5. Rinn JL, Chang HY. Genome Regulation by Long Noncoding RNAs. Annu Rev Biochem (2012) 81:145-66. doi: 10.1146/annurev-biochem-051410092902

6. Tian X, Tian J, Tang X, Ma J, Wang S. Long Non-Coding RNAs in the Regulation of Myeloid Cells. J Hematol Oncol (2016) 9:99. doi: 10.1186/ s13045-016-0333-7

7. Pathania AS, Prathipati P, Pandey MK, Byrareddy SN, Coulter DW, Gupta SC, et al. The Emerging Role of Non-Coding RNAs in the Epigenetic Regulation of Pediatric Cancers. Semin Cancer Biol (2021). doi: 10.1016/ j.semcancer.2021.04.015

8. Iyer MK, Niknafs YS, Malik R, Singhal U, Sahu A, Hosono Y, et al. The Landscape of Long Noncoding RNAs in the Human Transcriptome. Nat Genet (2015) 47:199-208. doi: 10.1038/ng.3192

9. Derrien T, Johnson R, Bussotti G, Tanzer A, Djebali S, Tilgner H, et al. The GENCODE V7 Catalog of Human Long Noncoding RNAs: Analysis of Their Gene Structure, Evolution, and Expression. Genome Res (2012) 22:1775-89. doi: $10.1101 /$ gr.132159.111

10. Ma L, Bajic VB, Zhang Z. On the Classification of Long Non-Coding RNAs. RNA Bio (2013) 10:925-33. doi: 10.4161/rna.24604

11. Bhan A, Soleimani M, Mandal SS. Long Noncoding RNA and Cancer: A New Paradigm. Cancer Res (2017) 77:3965-81. doi: 10.1158/00085472.CAN-16-2634

12. Wang KC, Chang HY. Molecular Mechanisms of Long Noncoding RNAs. Mol Cell (2011) 43:904-14. doi: 10.1016/j.molcel.2011.08.018

13. Tsagakis I, Douka K, Birds I, Aspden JL. Long Non-Coding RNAs in Development and Disease: Conservation to Mechanisms. J Pathol (2020) 250:480-95. doi: 10.1002/path.5405

14. Khan MR, Wellinger RJ, Laurent B. Exploring the Alternative Splicing of Long Noncoding RNAs. Trends Genet (2021) 37:695-8. doi: 10.1016/ j.tig.2021.03.010

15. Sur S, Ray RB. Emerging Role of lncRNA ELDR in Development and Cancer. FEBS J (2021). doi: 10.1111/febs.15876

16. Xing YH, Chen LL. Processing and Roles of snoRNA-Ended Long Noncoding RNAs. Crit Rev Biochem Mol Biol (2018) 53:596-606. doi: 10.1080/10409238.2018.1508411

17. Wang X, Hu X, Song W, Xu H, Xiao Z, Huang R, et al. Mutual Dependency Between IncRNA LETN and Protein NPM1 in Controlling the Nucleolar Structure and Functions Sustaining Cell Proliferation. Cell Res (2021) 31:664-83. doi: 10.1038/s41422-020-00458-6

18. Cho SW, Xu J, Sun R, Mumbach MR, Carter AC, Chen YG, et al. Promoter of IncRNA Gene PVT1 Is a Tumor-Suppressor DNA Boundary Element. Cell (2018) 173:1398-412.e22. doi: 10.1016/j.cell.2018.03.068

19. Tian X, Zheng Y, Yin K, Ma J, Tian J, Zhang Y, et al. LncRNA AK036396 Inhibits Maturation and Accelerates Immunosuppression of Polymorphonuclear Myeloid-Derived Suppressor Cells by Enhancing the Stability of Ficolin B. Cancer Immunol Res (2020) 8:565-77. doi: 10.1158/ 2326-6066.CIR-19-0595

20. Tian X, Shen H, Li Z, Wang T, Wang S. Tumor-Derived Exosomes, MyeloidDerived Suppressor Cells, and Tumor Microenvironment. J Hematol Oncol (2019) 12:84. doi: 10.1186/s13045-019-0772-z

21. Statello L, Guo CJ, Chen LL, Huarte M. Gene Regulation by Long NonCoding RNAs and Its Biological Functions. Nat Rev Mol Cell Biol (2021) 22:96-118. doi: 10.1038/s41580-020-00315-9

22. Xu CL, Sang B, Liu GZ, Li JM, Zhang XD, Liu LX, et al. SENEBLOC, a Long Non-Coding RNA Suppresses Senescence via P53-Dependent and Independent Mechanisms. Nucleic Acids Res (2020) 48:3089-102. doi: 10.1093/nar/gkaa063

23. Gil N, Ulitsky I. Regulation of Gene Expression by Cis-Acting Long Non-Coding RNAs. Nat Rev Genet (2020) 21:102-17. doi: 10.1038/s41576-019-0184-5

24. Sun Q, Hao Q, Prasanth KV. Nuclear Long Noncoding RNAs: Key Regulators of Gene Expression. Trends Genet (2018) 34:142-57. doi: 10.1016/j.tig.2017.11.005

25. He J, Li F, Zhou Y, Hou X, Liu S, Li X, et al. LncRNA XLOC_006390 Promotes Pancreatic Carcinogenesis and Glutamate Metabolism by Stabilizing C-Myc. Cancer Lett (2020) 469:419-28. doi: 10.1016/j.canlet.2019.11.021

26. Alvarez-Garcia V, Tawil Y, Wise HM, Leslie NR. Mechanisms of PTEN Loss in Cancer: It's All About Diversity. Semin Cancer Biol (2019) 59:66-79. doi: 10.1016/j.semcancer.2019.02.001

27. Lichtenstein AV. Genetic Mosaicism and Cancer: Cause and Effect. Cancer Res (2018) 78:1375-8. doi: 10.1158/0008-5472.CAN-17-2769

28. Nadeu F, Diaz-Navarro A, Delgado J, Puente XS, Campo E. Genomic and Epigenomic Alterations in Chronic Lymphocytic Leukemia. Annu Rev Pathol (2020) 15:149-77. doi: 10.1146/annurev-pathmechdis-012419-032810

29. Zhao SG, Chen WS, Li H, Foye A, Zhang M, Sjostrom M, et al. The DNA Methylation Landscape of Advanced Prostate Cancer. Nat Genet (2020) 52:778-89. doi: 10.1038/s41588-020-0648-8

30. Li Z, Lu X, Liu Y, Zhao J, Ma S, Yin H, et al. Gain of LINC00624 Enhances Liver Cancer Progression by Disrupting the Histone Deacetylase 6/Tripartite Motif Containing 28/Zinc Finger Protein 354c Corepressor Complex. Hepatol (2021) 73:1764-82. doi: 10.1002/hep.31530

31. Garzon R, Volinia S, Papaioannou D, Nicolet D, Kohlschmidt J, Yan PS et al. Expression and Prognostic Impact of lncRNAs in Acute Myeloid Leukemia. Proc Natl Acad Sci USA (2014) 111:18679-84. doi: 10.1073/ pnas. 1422050112

32. Takayama K, Horie-Inoue K, Katayama S, Suzuki T, Tsutsumi S, Ikeda K, et al. Androgen-Responsive Long Noncoding RNA CTBP1-AS Promotes Prostate Cancer. EMBO J (2013) 32:1665-80. doi: 10.1038/emboj.2013.99

33. Zheng Y, Tian X, Wang T, Xia X, Cao F, Tian J, et al. Long Noncoding RNA Pvt1 Regulates the Immunosuppression Activity of Granulocytic Myeloid- 
Derived Suppressor Cells in Tumor-Bearing Mice. Mol Cancer (2019) 18:61. doi: 10.1186/s12943-019-0978-2

34. Tian X, Ma J, Wang T, Tian J, Zheng Y, Peng R, et al. Long Non-Coding RNA RUNXOR Accelerates MDSC-Mediated Immunosuppression in Lung Cancer. BMC Cancer (2018) 18:660. doi: 10.1186/s12885-018-4564-6

35. Tian X, Ma J, Wang T, Tian J, Zhang Y, Mao L, et al. Long Non-Coding RNA HOXA Transcript Antisense RNA Myeloid-Specific 1-HOXA1 Axis Downregulates the Immunosuppressive Activity of Myeloid-Derived Suppressor Cells in Lung Cancer. Front Immunol (2018) 9:473. doi: 10.3389/fimmu.2018.00473

36. Xu L, Liu W, Li T, Hu Y, Wang Y, Huang L, et al. Long Non-Coding RNA SMASR Inhibits the EMT by Negatively Regulating TGF-Beta/Smad Signaling Pathway in Lung Cancer. Oncogene (2021) 40:3578-92. doi: 10.1038/s41388-021-01760-2

37. Hua JT, Chen S, He HH. Landscape of Noncoding RNA in Prostate Cancer. Trends Genet (2019) 35:840-51. doi: 10.1016/j.tig.2019.08.004

38. Huang Z, Zhou JK, Peng Y, He W, Huang C. The Role of Long Noncoding RNAs in Hepatocellular Carcinoma. Mol Cancer (2020) 19:77. doi: 10.1186/ s12943-020-01188-4

39. Lin C, Yang L. Long Noncoding RNA in Cancer: Wiring Signaling Circuitry. Trends Cell Biol (2018) 28:287-301. doi: 10.1016/j.tcb.2017.11.008

40. Huarte M. The Emerging Role of lncRNAs in Cancer. Nat Med (2015) 21:1253-61. doi: 10.1038/nm.3981

41. Wang H, Meng Q, Ma B. Characterization of the Prognostic M6a-Related IncRNA Signature in Gastric Cancer. Front Oncol (2021) 11:630260. doi: $10.3389 /$ fonc. 2021.630260

42. Vidovic D, Huynh TT, Konda P, Dean C, Cruickshank BM, Sultan M, et al. ALDH1A3-Regulated Long Non-Coding RNA NRAD1 Is a Potential Novel Target for Triple-Negative Breast Tumors and Cancer Stem Cells. Cell Death Differ (2020) 27:363-78. doi: 10.1038/s41418-019-0362-1

43. Chen Y, Cheng WY, Shi H, Huang S, Chen H, Liu D, et al. Classifying Gastric Cancer Using FLORA Reveals Clinically Relevant Molecular Subtypes and Highlights LINC01614 as a Biomarker for Patient Prognosis. Oncogene (2021) 40:2898-909. doi: 10.1038/s41388-021-01743-3

44. Li N, Yang G, Luo L, Ling L, Wang X, Shi L, et al. IncRNA THAP9-AS1 Promotes Pancreatic Ductal Adenocarcinoma Growth and Leads to a Poor Clinical Outcome via Sponging miR-484 and Interacting With YAP. Clin Cancer Res (2020) 26:1736-48. doi: 10.1158/1078-0432.CCR-19-0674

45. Liu X, Xiao ZD, Han L, Zhang J, Lee SW, Wang W, et al. LncRNA NBR2 Engages a Metabolic Checkpoint by Regulating AMPK Under Energy Stress. Nat Cell Biol (2016) 18:431-42. doi: 10.1038/ncb3328

46. Xu CF, Brown MA, Nicolai H, Chambers JA, Griffiths BL, Solomon E. Isolation and Characterisation of the NBR2 Gene Which Lies Head to Head With the Human BRCA1 Gene. Hum Mol Genet (1997) 6:1057-62. doi: $10.1093 / \mathrm{hmg} / 6.7 .1057$

47. Deng CX. Roles of BRCA1 in Centrosome Duplication. Oncogene (2002) 21:6222-7. doi: 10.1038/sj.onc. 1205713

48. Billack B, Monteiro AN. BRCA1 in Breast and Ovarian Cancer Predisposition. Cancer Lett (2005) 227:1-7. doi: 10.1016/j.canlet.2004.11.006

49. Miki Y, Swensen J, Shattuck-Eidens D, Futreal PA, Harshman K, Tavtigian S, et al. A Strong Candidate for the Breast and Ovarian Cancer Susceptibility Gene BRCA1. Science (1994) 266:66-71. doi: 10.1126/science.7545954

50. Sefton P. Testing for BRCA1/2 Mutations. JAMA (2017) 318:2054. doi: 10.1001/jama.2017.17280

51. Xiao ZD, Liu X, Zhuang L, Gan B. NBR2: A Former Junk Gene Emerges as a Key Player in Tumor Suppression. Mol Cell Oncol (2016) 3:e1187322. doi: $10.1080 / 23723556.2016 .1187322$

52. Xu CF, Solomon E. Mutations of the BRCA1 Gene in Human Cancer. Semin Cancer Biol (1996) 7:33-40. doi: 10.1006/scbi.1996.0005

53. Narod SA, Foulkes WD. BRCA1 and BRCA2: 1994 and Beyond. Nat Rev Cancer (2004) 4(9):665-76. doi: 10.1038/nrc1431

54. Dimitrov S, Brennerova M, Forejt J. Expression Profiles and Intergenic Structure of Head-to-Head Oriented Brcal and Nbrl Genes. Gene (2001) 262:89-98. doi: 10.1016/s0378-1119(00)00549-7

55. Brown MA, Xu CF, Nicolai H, Griffiths B, Chambers JA, Black D, et al. The 5 ' End of the BRCA1 Gene Lies Within a Duplicated Region of Human Chromosome 17q21. Oncogene (1996) 12:2507-13.
56. Kirkin V, Lamark T, Sou YS, Bjorkoy G, Nunn JL, Bruun JA, et al. A Role for NBR1 in Autophagosomal Degradation of Ubiquitinated Substrates. Mol Cell (2009) 33:505-16. doi: 10.1016/j.molcel.2009.01.020

57. Sanchez-Martin P, Sou YS, Kageyama S, Koike M, Waguri S, Komatsu M. NBR1-Mediated P62-Liquid Droplets Enhance the Keap1-Nrf2 System. EMBO Rep (2020) 21:e48902. doi: 10.15252/embr.201948902

58. Cerda-Troncoso C, Varas-Godoy M, Burgos PV. Pro-Tumoral Functions of Autophagy Receptors in the Modulation of Cancer Progression. Front Oncol (2021) 10:619727. doi: 10.3389/fonc.2020.619727

59. Liu YM, Ma JH, Zeng QL, Lv J, Xie XH, Pan YJ, et al. MiR-19a Affects Hepatocyte Autophagy via Regulating IncRNA NBR2 and AMPK/ PPARalpha in D-GalN/Lipopolysaccharide-Stimulated Hepatocytes. J Cell Biochem (2018) 119:358-65. doi: 10.1002/jcb.26188

60. Zhu C, He X, Chen K, Huang Z, Yao A, Tian X, et al. LncRNA NBR2 Aggravates Hepatoblastoma Cell Malignancy and Promotes Cell Proliferation Under Glucose Starvation Through the miR-22/TCF7 Axis. Cell Cycle (2021) 20:575-90. doi: 10.1080/15384101.2021.1885236

61. Dimitrov SD, Matouskova E, Forejt J. Expression of BRCA1, NBR1 and NBR2 Genes in Human Breast Cancer Cells. Folia Biol (Praha) (2001) 47:120-7.

62. Xu CF, Chambers JA, Solomon E. Complex Regulation of the BRCA1 Gene. J Biol Chem (1997) 272:20994-7. doi: 10.1074/jbc.272.34.20994

63. Suen TC, Goss PE. Identification of a Novel Transcriptional Repressor Element Located in the First Intron of the Human BRCA1 Gene. Oncogene (2001) 20:440-50. doi: 10.1038/sj.onc.1204078

64. Suen TC, Tang MS, Goss PE. Model of Transcriptional Regulation of the BRCA1-NBR2 Bi-Directional Transcriptional Unit. BBA (2005) 1728:12634. doi: 10.1016/j.bbaexp.2005.01.014

65. Suen TC, Goss PE. Transcription of BRCA1 Is Dependent on the Formation of a Specific Protein-DNA Complex on the Minimal BRCA1 Bi-Directional Promoter. J Biol Chem (1999) 274:31297-304. doi: 10.1074/jbc.274.44.31297

66. Auriol E, Billard LM, Magdinier F, Dante R. Specific Binding of the Methyl Binding Domain Protein 2 at the BRCA1-NBR2 Locus. Nucleic Acids Res (2005) 33:4243-54. doi: 10.1093/nar/gki729

67. Wade PA. Methyl CpG-Binding Proteins and Transcriptional Repression. Bioessays (2001) 23:1131-7. doi: 10.1002/bies.10008

68. Baxevanis CN, Fortis SP, Perez SA. The Balance Between Breast Cancer and the Immune System: Challenges for Prognosis and Clinical Benefit From Immunotherapies. Semin Cancer Biol (2021) 72:76-89. doi: 10.1016/ j.semcancer.2019.12.018

69. Wiedmeier JE, Ohlrich A, Chu A, Rountree MR, Turker MS. Induction of the Long Noncoding RNA NBR2 From the Bidirectional BRCA1 Promoter Under Hypoxic Conditions. Mutat Res (2017) 796:13-9. doi: 10.1016/ j.mrfmmm.2017.02.001

70. Lu Y, Chu A, Turker MS, Glazer PM. Hypoxia-Induced Epigenetic Regulation and Silencing of the BRCA1 Promoter. Mol Cell Biol (2011) 31:3339-50. doi: 10.1128/MCB.01121-10

71. Liu X, Gan B. IncRNA NBR2 Modulates Cancer Cell Sensitivity to Phenformin Through GLUT1. Cell Cycle (2016) 15:3471-81. doi: 10.1080/ 15384101.2016 .1249545

72. Yu H, Xie Y, Zhou Z, Wu Z, Dai X, Xu B. Curcumin Regulates the Progression of Colorectal Cancer via LncRNA NBR2/AMPK Pathway. Technol Cancer Res Treat (2019) 18:1533033819870781. doi: 10.1177/1533033819870781

73. Liu X, Xiao ZD, Gan B. An IncRNA Switch for AMPK Activation. Cell Cycle (2016) 15:1948-9. doi: 10.1080/15384101.2016.1184515

74. Pavlova NN, Thompson CB. The Emerging Hallmarks of Cancer Metabolism. Cell Metab (2016) 23:27-47. doi: 10.1016/j.cmet.2015.12.006

75. Li Q, Wang Y, Wu S, Zhou Z, Ding X, Shi R, et al. CircACC1 Regulates Assembly and Activation of AMPK Complex Under Metabolic Stress. Cell Metab (2019) 30:157-73.e7. doi: 10.1016/j.cmet.2019.05.009

76. Laplante M, Sabatini DM. mTOR Signaling in Growth Control and Disease. Cell (2012) 149:274-93. doi: 10.1016/j.cell.2012.03.017

77. Hardie DG, Schaffer BE, Brunet A. AMPK: An Energy-Sensing Pathway With Multiple Inputs and Outputs. Trends Cell Biol (2016) 26:190-201. doi: 10.1016/j.tcb.2015.10.013

78. Kim J, Kundu M, Viollet B, Guan KL. AMPK and mTOR Regulate Autophagy Through Direct Phosphorylation of Ulk1. Nat Cell Biol (2011) 13:132-41. doi: 10.1038/ncb2152 
79. Sharma RA, Euden SA, Platton SL, Cooke DN, Shafayat A, Hewitt HR, et al. Phase I Clinical Trial of Oral Curcumin: Biomarkers of Systemic Activity and Compliance. Clin Cancer Res (2004) 10:6847-54. doi: 10.1158/10780432.CCR-04-0744

80. Zhang X, Lin HK. NBR2-GLUT1 Axis Regulates Cancer Cell Sensitivity to Biguanides. Cell Cycle (2017) 16:249-50. doi: 10.1080/15384101.2016.1263498

81. Eichenmuller M, Trippel F, Kreuder M, Beck A, Schwarzmayr T, Haberle B, et al. The Genomic Landscape of Hepatoblastoma and Their Progenies With HCCLike Features. J Hepatol (2014) 61:1312-20. doi: 10.1016/j.jhep.2014.08.009

82. Gebhardt R, Hovhannisyan A. Organ Patterning in the Adult Stage: The Role of Wnt/beta-Catenin Signaling in Liver Zonation and Beyond. Dev Dyn (2010) 239:45-55. doi: 10.1002/dvdy.22041

83. Clevers H, Nusse R. Wnt/beta-Catenin Signaling and Disease. Cell (2012) 149:1192-205. doi: 10.1016/j.cell.2012.05.012

84. Dongre A, Weinberg RA. New Insights Into the Mechanisms of EpithelialMesenchymal Transition and Implications for Cancer. Nat Rev Mol Cell Biol (2019) 20:69-84. doi: 10.1038/s41580-018-0080-4

85. Lamouille S, Xu J, Derynck R. Molecular Mechanisms of EpithelialMesenchymal Transition. Nat Rev Mol Cell Biol (2014) 15:178-96. doi: $10.1038 / \mathrm{nrm} 3758$

86. Gugnoni M, Ciarrocchi A. Long Noncoding RNA and Epithelial Mesenchymal Transition in Cancer. Int J Mol Sci (2019) 20:1924. doi: 10.3390/ijms20081924

87. Gao YP, Li Y, Li HJ, Zhao B. LncRNA NBR2 Inhibits EMT Progression by Regulating Notch1 Pathway in NSCLC. Eur Rev Med Pharmacol Sci (2019) 23:7950-8. doi: 10.26355/eurrev_201909_19011

88. Bai J, Xu J, Zhao J, Zhang R. LncRNA NBR2 Suppresses Migration and Invasion of Colorectal Cancer Cells by Downregulating miRNA-21. Hum Cell (2020) 33:98-103. doi: 10.1007/s13577-019-00265-1

89. Cai W, Wu B, Li Z, He P, Wang B, Cai A, et al. LncRNA NBR2 Inhibits Epithelial-Mesenchymal Transition by Regulating Notch1 Signaling in Osteosarcoma Cells. J Cell Biochem (2018). doi: 10.1002/jcb.27508

90. Yang W, Zheng Z, Yi P, Wang S, Zhang N, Ming J, et al. LncRNA NBR2 Inhibits the Malignancy of Thyroid Cancer, Associated With Enhancing the AMPK Signaling. Front Oncol (2020) 10:956. doi: 10.3389/fonc.2020.00956

91. Derynck R, Weinberg RA. EMT and Cancer: More Than Meets the Eye. Dev Cell (2019) 49:313-6. doi: 10.1016/j.devcel.2019.04.026

92. Levine B, Mizushima N, Virgin HW. Autophagy in Immunity and Inflammation. Nat (2011) 469:323-35. doi: 10.1038/nature09782

93. Wu SY, Lan SH, Wu SR, Chiu YC, Lin XZ, Su IJ, et al. Hepatocellular Carcinoma-Related Cyclin D1 Is Selectively Regulated by Autophagy Degradation System. Hepatol (2018) 68:141-54. doi: 10.1002/hep.29781

94. Song J, Qu Z, Guo X, Zhao Q, Zhao X, Gao L, et al. Hypoxia-Induced Autophagy Contributes to the Chemoresistance of Hepatocellular Carcinoma Cells. Autophagy (2009) 5:1131-44. doi: 10.4161/auto.5.8.9996

95. Sheng JQ, Wang MR, Fang D, Liu L, Huang WJ, Tian DA, et al. LncRNA NBR2 Inhibits Tumorigenesis by Regulating Autophagy in Hepatocellular Carcinoma. BioMed Pharmacother (2021) 133:111023. doi: 10.1016/j.biopha.2020.111023

96. Li X, He S, Ma B. Autophagy and Autophagy-Related Proteins in Cancer. Mol Cancer (2020) 19:12. doi: 10.1186/s12943-020-1138-4
97. Wang X, Han L, Zhou L, Wang L, Zhang LM. Prediction of Candidate RNA Signatures for Recurrent Ovarian Cancer Prognosis by the Construction of an Integrated Competing Endogenous RNA Network. Oncol Rep (2018) 40:2659-73. doi: 10.3892/or.2018.6707

98. Hamdi Y, Ben Rekaya M, Jingxuan S, Nagara M, Messaoud O, Benammar Elgaaied A, et al. A Genome Wide SNP Genotyping Study in the Tunisian Population: Specific Reporting on a Subset of Common Breast Cancer Risk Loci. BMC cancer (2018) 18:1295. doi: 10.1186/s12885-018-5133-8

99. Brown MA, Lo LJ, Catteau A, Xu CF, Lindeman GJ, Hodgson S, et al. Germline BRCA1 Promoter Deletions in UK and Australian Familial Breast Cancer Patients: Identification of a Novel Deletion Consistent With BRCA1: psiBRCA1 Recombination. Hum Mutat (2002) 19:435-42. doi: 10.1002/ humu. 10055

100. Gad S, Bieche I, Barrois M, Casilli F, Pages-Berhouet S, Dehainault C, et al. Characterisation of a $161 \mathrm{~Kb}$ Deletion Extending From the NBR1 to the BRCA1 Genes in a French Breast-Ovarian Cancer Family. Hum Mutat (2003) 21:654. doi: 10.1002/humu.9148

101. Garcia-Casado Z, Romero I, Fernandez-Serra A, Rubio L, Llopis F, Garcia A, et al. A De Novo Complete BRCA1 Gene Deletion Identified in a Spanish Woman With Early Bilateral Breast Cancer. BMC Med Genet (2011) 12:134. doi: 10.1186/1471-2350-12-134

102. Rizza R, Hackmann K, Paris I, Minucci A, De Leo R, Schrock E, et al. Novel BRCA1 Large Genomic Rearrangements in Italian Breast/Ovarian Cancer Patients. Mol Diagn Ther (2019) 23:121-6. doi: 10.1007/s40291-018-0376-2

103. Zhang J, Jiang H, Feng X, Wang L, Yang X. NBR2 Promotes the Proliferation of Glioma Cells via Inhibiting P15 Expression. J BUON (2021) 26:388-94.

104. Yan J, Chen D, Chen X, Sun X, Dong Q, Hu C, et al. Downregulation of IncRNA CCDC26 Contributes to Imatinib Resistance in Human Gastrointestinal Stromal Tumors Through IGF-1R Upregulation. Braz J Med Biol Res (2019) 52:e8399. doi: 10.1590/1414-431×20198399

105. Donepudi MS, Kondapalli K, Amos SJ, Venkanteshan P. Breast Cancer Statistics and Markers. J Cancer Res Ther (2014) 10:506-11. doi: 10.4103/ 0973-1482.137927

Conflict of Interest: The authors declare that the research was conducted in the absence of any commercial or financial relationships that could be construed as a potential conflict of interest.

Publisher's Note: All claims expressed in this article are solely those of the authors and do not necessarily represent those of their affiliated organizations, or those of the publisher, the editors and the reviewers. Any product that may be evaluated in this article, or claim that may be made by its manufacturer, is not guaranteed or endorsed by the publisher.

Copyright $\odot 2021$ Wang, Li, Yan, Yan, Shen and Tian. This is an open-access article distributed under the terms of the Creative Commons Attribution License (CC BY). The use, distribution or reproduction in other forums is permitted, provided the original author(s) and the copyright owner(s) are credited and that the original publication in this journal is cited, in accordance with accepted academic practice. No use, distribution or reproduction is permitted which does not comply with these terms. 